\title{
Nutritional Status, Sarcopenia and the Importance of Prehabilitation of Gastrointestinal Tumor Patients: a Surgical Point of View
}

\author{
Péter Lukovich, Ákos Nagy, Bianka Barok, Borbála Csiba, Ram Rokka, Balázs Pőcze \\ Department of Surgery, St. John Hospital, Diós árok 1-3, 1125 Budapest, Hungary
}

\begin{abstract}
Background Surgery may be the field of healthcare where malnutrition and sarcopenia have their greatest impact on patient morbidity and mortality. However, there are limited data on the nutritional status of surgical patients and the effects of prehabilitation on the outcomes of surgery. Methods A prospective analysis was conducted on all patients surgically-treated for malignant gastrointestinal tumors at St. John Hospital during a two-year period. The patient's gender, age, body weight, height, BMI and weight loss were registered, then a risk score was determined by the MUST survey. Measurement of the triceps and thigh skin-fold thickness and the circumference of the upper arm and thigh were done to calculate muscle area and muscle index, respectively. The body composition was assessed using an OMRON-BF511 device. Muscle function was evaluated based on hand clamping force measurement and activity tests. Patients who were diagnosed as being at-risk received preoperative prehabilitation, which included physiotherapy and nutritional therapy. Results A total of 231 patients (133 males/98 females) were analyzed. They had a mean age of 68.9 years (18 98). Seventy-four patients (32\%) lost weight, with an average loss of 7 kilograms (3 15 kg). Anthropometric data showed an average upper-arm circumference of $27.4 \mathrm{~cm}(14.3 \sim 38.1)$ and thigh circumference of $44.7 \mathrm{~cm}$ (19.3 60.1), so the median muscle index was 1.29. The mean BMI was 26 , which is above normal, and the elevated BMI was consistent documented in each patient subgroup stratified by age and tumor type. A body composition analysis was performed for 75 patients (44 male/31 female), who had a median age of 68 (37 88 y). The average BMI of these patients was $25.7 \mathrm{y}$ and their average MUST score was 1.12 . The total body fat percentage (of the total body mass) was $29.5 \%$, total muscle was $30.1 \%$ and visceral fat was $10 \%$. Thirty patients $(40 \%)$ had sarcopenia, with a mean BMI of 28.7 , fat comprising $34.2 \%$ of the body mass, visceral-fat $11 \%$, and muscle $27.1 \%$, and their median MUST score was 1.23. Patients who received preoperative training (physiotherapy) showed improvements in physical function ranging from $12 \% \sim 33 \%$. Conclusion Gastrointestinal tumor patients have a higher than normal BMI regardless of age or tumor type. Patients with sarcopenia show measurable improvement after two weeks of prehabilitation.
\end{abstract}

Key words: Sarcopenia; Surgery; Gastrointestinal tumor; Prehabilitation; Obesity; Nutritional therapy

\section{Introduction}

Unplanned weight loss is a specific characteristic of patients with gastrointestinal tumors, and may be caused by multiple tumor-related causes: loss of appetite, nausea, and other digestion-related complaints, while increased catabolism of tumor tissue results in intensified calorie consumption. Malnutrition is thus common in patients with gastrointestinal tumors, and has particular significance with regard to surgery. The process of abdominal wall healing and bowel anastomosis requires considerable extra calories and protein intake. Weight loss also leads to deterioration of the immune function, increasing the incidence of infections like urinary tract infections or pneumonia $[1,2]$. It has been estimated that patients with malnutrition have a 1.25 -fold higher rate for complications and a 2.15 -fold increased mortality risk compared to well-nourished patients [3]. Apart from the diagnosis of malnutrition, the presence of sarcopenia [4] (loss of muscle mass) has particular

Corresponding author: Péter Lukovich MD, PhD, Department of Surgery, St. John Hospital, Diós árok 1-3, 1125 Budapest, Hungary; Tel: +36 1458 4500; Fax +36 1458 4656; Email: lukovich66@gmail. com significance due to its role in increasing morbidity and mortality rates in both surgical and oncology patients. $[5,6]$ These points emphasize the relevance of preoperative nutritional assessment and recognition of cancer-related malnutrition and sarcopenia.

Several methods have been used for assessing the risk of malnutrition (nourishment history, questionnaire-based surveys, laboratory tests, anthropometric measurements, body composition measurement, etc.), all of which have both advantages and disadvantages [6]. Despite the recognition that nutrition is important, only limited data are available on the nutritional condition of gastrointestinal tumor patients prior to surgery. An assessment of the risk and the development of strategies to reduce the risk can help to optimize the surgical treatment algorithm for abdominal cancer patients.

\section{Methods}

Our prospective research included all of the patients who were admitted to the Surgical Department of St. John Hospital diagnosed with a malignant gastrointestinal tumor. Demographic (gender, age) and morphologic 
(body weight, height) data were recorded and the BMI was calculated. We recorded the amount of weight loss within the past six months and used the MUST survey to determine a risk score for each patient. The patients whose MUST score was 2 or more received preoperative nutritional treatment.

To assess the muscle mass of patients, a caliper was used to measure the triceps skin-fold thickness and the upper arm circumference, then the thigh skin-fold thickness and girth were also evaluated. The areas of the upper arm and thigh cross-sections were calculated from the measured circumferences. The muscle proportion was computed as the limb cross-section area minus the subcutaneous tissue area, which was derived from the skin-fold data. These results were divided by the body height, which yielded an individual and characteristic parameter, the "muscle index" which is suitable for following patient body changes (Circumference 2/4 $\pi=\operatorname{limb}$ area; limb area $-\pi \times$ skinfold thickness $=$ muscle perimeter; muscle perimeter $2 / 4 \pi$ $=$ muscle area). The patients' muscle index was generally a number between 0 and 2, and a number less than 1 was considered to indicate sarcopenia.

The body composition was measured with an OMRON BF 511 device. Muscle function was determined by four methods, one was the hand clamping force measurement (Camry Digital Hand Dynamometer SCACAM-EH10117; South El Monte, CA, USA), which was performed for both the left and right sides. The second method was a 6 minute walking test, then a 30 second sit-and-stand test was done, and finally a 2 minute step test was performed.

All patients with sarcopenia received preoperative dietary plus individual physiotherapy as a part of the prehabilitation approach. These interventions could be performed individually at their home. Since every patient was capable of oral intake, daily enteral nutrition (containing additional $700 \sim 800 \mathrm{kcal}$ energy) was administered. The enteral nutrition was a protein-rich oral nutritional liquid supplement, with a special formula provided for diabetic patients. Additionally, each patient consulted a dietitian, who provided recommendations for how to consume a protein-rich diet.

The main purpose of preoperative physiotherapy was to improve the aerobic and cardiopulmonary condition of the patient. The coached exercises for patients comprised a 35 -second muscle work-out, followed by an interval 25 seconds of resting, with goose-steps to relieve the heart rate.

The GraphPad 9 program was used for statistical calculations, and significance was determined by the MannWhitney $U$-test and $t$-tests.

\section{Results}

A total of 231 gastrointestinal tumor patients (133 males, 98 females) were included in our prospective analysis. The average age was 68.9 years (range 18 to 98 ). Seventy-four patients had mentioned unplanned weight loss, with an average loss of $7 \mathrm{~kg}$ (range 3 to $15 \mathrm{~kg}$ ). The mean BMI of all patients was $26.4 \mathrm{y}$.

BMI data were analyzed specifically in relation to tumor types. Twenty-two patients with gastric tumors had a mean BMI of $25.3 \mathrm{~kg} / \mathrm{m}^{2}$, the 11 pancreatic tumor patients had a BMI of $28.7 \mathrm{~kg} / \mathrm{m}^{2}$. There were 29 patients with liver tumors, who had a mean BMI of $29.1 \mathrm{~kg} / \mathrm{m}^{2}$. The 48 patients with right colon cancer had an average BMI of 26.1 $\mathrm{kg} / \mathrm{m}^{2}$, while the 121 patients with left colon cancer had an average BMI of $26.7 \mathrm{~kg} / \mathrm{m}^{2}$ (Table 1).

Table 1 BMI score and weight loss in gastrointestinal tumor patients.

\begin{tabular}{lcccc}
\hline Tumor type & $\begin{array}{c}\text { Number of } \\
\text { cases }\end{array}$ & $\begin{array}{c}\text { BMI } \\
\left(\mathbf{k g} / \mathbf{m}^{2}\right)\end{array}$ & $\begin{array}{c}\text { BMI } \\
\text { SD }\end{array}$ & $\begin{array}{c}\text { Weight loss, } \\
\text { mean }(\mathbf{k g})\end{array}$ \\
\hline Liver tumor & 29 & 29.1 & 3.13 & 2.4 \\
Gastric tumor & 22 & 25.3 & 2.50 & 8.4 \\
Pancreatic tumor & 11 & 28.7 & 4.08 & 13.0 \\
Right colon tumor & 48 & 26.1 & 3.12 & 4.2 \\
Left colon tumor & 121 & 26.7 & 4.96 & 5.0 \\
\hline
\end{tabular}

\section{Anthropometric data}

The normal skin-fold thickness is $1.13 \sim 1.37 \mathrm{~cm}$ for men and $1.49 \sim 1.81 \mathrm{~cm}$ for women. In our study, the triceps skinfold thickness was a mean of $1.61 \mathrm{~cm}$ (range 0.6 to 3.8 ) for men and $2.09 \mathrm{~cm}$ (range 0.8 to 4.2 ) for women. Further anthropometric evaluation revealed that the mean upper arm circumference was $31.13 \mathrm{~cm}$ (range 19 to 42.1) and the thigh circumference was $51.88 \mathrm{~cm}$ (range 36.2 to 69.1) for male patients, while the average thigh skin-fold thickness was $1.48 \mathrm{~cm}$ (range 0.6 to 3.8 ). For female patients, the average upper arm circumference was $28.7 \mathrm{~cm}$ (range 18 to 39.2) and the average thigh circumference was $50.8 \mathrm{~cm}$ (range 33.3 to 63.3 ). The thigh skin-fold thickness was 2.92 cm (range 0.8 to 5.3 ).

The mean muscle index for male and female patients was 1.33 and 1.13, respectively. Using a cut-off of muscle index $<1.43$ of the 231 patients had sarcopenia.

\section{Hand clamping force measurement}

Hand clamping force measurements were performed for all patients. According to the measurements, 133 men had a mean clamping force of $37.3 \mathrm{~kg}$ (range 12.4 to 57.2), while 98 women had a mean force of $24.6 \mathrm{~kg}$ in average (range 8.4 to 40.1). Both gender groups performed within the normal range. Patients were older than 70 were categorized and analyzed separately. A total of 70 male patients were older than 70, and had an average hand clamping force of $18.9 \mathrm{~kg}$, which is lower than normal (normal range: $21.3 \sim 35.1 \mathrm{~kg}$ ). Fifty female patients were older than 70 , and their average result was $12.8 \mathrm{~kg}$, which was also lower than normal (normal range 14.7 24.5 kg). 


\section{Preoperative nutritional therapy}

Fifty-eight of the 231 patients received an average of 11.9 days of preoperative nutritional therapy. Although one patient lost weight during this treatment, all of the others remained at the same body weight or gained some additional weight.

\section{Preoperative physiotherapy}

Among the 58 patients who received preoperative nutritional therapy, 33 also received preoperative physiotherapy. The three functional tests were performed after the physiotherapy program, and showed an improved performance. The average result for the 6 minutes walking test had been 344 meters during the primary evaluation, and was an average of 389 meters a mean 23.2 days later, right before surgery. The mean 30 seconds sit-and-stand test result was 9 repetitions during the first evaluation and was an average of 12 the second time. The 2 minutes step test had an average of 104 knee lifts during first evaluation, which increased to 116 after the preoperative training. Overall, the physical function of the patients was improved $12 \% \sim 33 \%$ by the physiotherapy program (Table 2 ).

Table 2 Functional test results and progression in performance.

\begin{tabular}{lcccc}
\hline $\begin{array}{l}\text { Functional } \\
\text { tests } \\
(\mathbf{n}=\mathbf{3 3})\end{array}$ & $\begin{array}{l}\text { Primary } \\
\text { evaluation }\end{array}$ & $\begin{array}{l}\text { Secondary } \\
\text { evaluation } \\
\text { (preoperative) }\end{array}$ & $\begin{array}{l}\text { Prog- } \\
\text { ress }\end{array}$ & $\boldsymbol{P}$ \\
\hline $\begin{array}{l}6 \text { minutes walk- } \\
\text { ing test }\end{array}$ & 344 meter- & 389 meter- & $13 \%$ & 0.323 \\
$\begin{array}{l}30 \text { seconds sit- } \\
\text { and -stand test }\end{array}$ & 9 repetitions & 12 repetitions & $33 \%$ & $<0.05$ \\
$\begin{array}{l}2 \text { minutes step } \\
\text { test }\end{array}$ & 104 repetitions & 116 repetitions & $12 \%$ & 0.35 \\
\hline
\end{tabular}

\section{Body composition assessment}

A body composition assessment was done in 75 patients. The average age of these patients was 68 years (range 37 to 88 ), and there were 44 men and 31 women. The mean BMI was $25.7 \mathrm{~kg} / \mathrm{m}^{2}$ and the average MUST score was 1.12. Twenty-six (34.7\%) of these patients reported weight loss (mean $7 \mathrm{~kg}$ ), and the median MUST score was 1.92 for these patients. According to the measurements performed with the OMRON device, the total body fat was $29.5 \%$ of the mass, total muscle was $30.1 \%$ and visceral-fat was $10 \%$. Among analyzed patients, $30(40 \%)$ had sarcopenia. The mean BMI was 28.7 in these patients, while the fat content was $34.2 \%$ of the body mass, visceral-fat was $11 \%$ and muscle was $27.1 \%$. The mean MUST score was 1.23 in the patients with sarcopenia (Table 3 ).

\section{Discussion}

A new challenge in the 21th century is the anticipated expansion of the human lifespan [8]. Increasing age leads not only to an increased incidence and severity of benign disorders, but also an increasing prevalence of gastrointestinal (colorectal, liver, gastric and pancreatic) tumors [9]. This increase in age is important, because the incidence of malignant tumors in people at age 85 is currently triple that at age 50 .

Table 3 Body composition assessment data.

\begin{tabular}{lccc}
\hline $\begin{array}{l}\text { Body composi- } \\
\text { tion assessment }\end{array}$ & $\begin{array}{c}\text { All patients } \\
(\mathbf{n}=\mathbf{7 5})\end{array}$ & $\begin{array}{c}\text { Patients with } \\
\text { sarcopenia }(\mathbf{n}=\mathbf{3 0})\end{array}$ & $\boldsymbol{P}$ \\
\hline BMI $\left(\mathrm{kg} / \mathrm{m}^{2}\right)$ & 25.7 & 28.7 & 0.18 \\
MUST & 1.12 & 1.23 & 0.213 \\
Total body-fat \% & 29.5 & 34.2 & $<0.05$ \\
Muscle \% & 30.1 & 27.1 & $<0.05$ \\
Visceral-fat \% & 10 & 11 & 0.378 \\
\hline
\end{tabular}

The body composition percentages were based on an analysis using the OMRON device.

Patients with a low skeletal muscle percentage were diagnosed to have sarcopenia

In more than $99 \%$ of patients with malignant gastrointestinal tumors, surgery represents the only possible curative solution. Older people have a greater risk of surgical complications due to a variety of causes, including the increased prevalence of chronic diseases like ischemic cardiopathy, diabetes mellitus and bronchopulmonary disorders $[10,11]$.

It is also known that patients with a higher BMI are more likely to suffer postoperative thromboembolic complications, deep vein thrombosis and pulmonary embolism [12]. Interestingly, patients with sarcopenia who have a higher visceral-fat ratio have a lower mortality rate than those with lower ratios [13]. Another factor associated with postoperative complications is the presence of sarcopenia, which is more common in elderly people. Body muscle mass reaches its peak at age 25 and starts to decline slowly, such that at age 70 , only $70 \%$ of the former muscle mass remains [14]. One additional factor resulting in a higher surgical risk is the need for emergency surgery, which is more common in older patients $[15,16]$.

There is strong evidence that patients who have lost weight before surgery should receive preoperative nutritional therapy for at least two weeks [17]. It is also becoming clear that nutritional therapy alone is not enough, and that physiotherapy (prehabilitation) is also necessary for resolving sarcopenia. It is recommended that at least four weeks of training be provided [18] - although our results showed a $12 \% \sim 33 \%$ improvement in the results of functional tests after just two weeks of intensive prehabilitation work for cooperative patients.

Upon the specific diagnosis of a malignant gastrointestinal tumor, a 2- to 4-week period of prehabilitation before surgery should be able to ensure that the patient is 
in a more suitable nutritional and fitness condition, without missing the opportunity for curative resection. As such, preoperative nutritional therapy should be started when the first relevant complaints appear (i.e., it should be started at the first consultation about the possible diagnosis). In addition, it should be kept in mind that cancer patients who have a normal or elevated BMI may still be malnourished and/or sarcopenic. Weight loss of $4 \% \sim 5 \%$ of the body weight is associated with medium risk based on the MUST calculation, and is a risk factor even if the patient would be classified as obese based on the BMI. This negative balance means that there is a notably higher perioperative risk.

It has been estimated that a typical gastrointestinal surgery results in a loss of calories. Recent surgical advances can help to reduce perioperative protein loss by applying minimally-invasive surgical techniques and methods in combination with newly-developed surgical devices. For example, the use of novel surgical cutting devices reduces blood loss. A $100 \mathrm{ml}$ aliquot of blood contains 5.5 8 g of protein, so reduced blood loss results in less protein loss. An advantage of fast track surgery is the absence of laxative preparation of the colon before surgery, which typically leads to a calorie waste of 1.5 to 2 day's intake for patients. The use of a laparoscopic approach for procedures requires smaller incisions on skin and the abdominal wall. These small incisions result in smaller wound surfaces that demand a lower amount of calories and protein. A good nutritional condition has significance beyond surgery. In cases that require adjuvant chemotherapy, the tolerance of therapy is lower in malnourished patients, which can lead to treatment being delayed or even cancelled [19].

Hungary is the second most obese in Europe, with obesity affecting $26.4 \%$ of the adult population, according to the most recent data available from the World Health Organization as of March 26, 2020 [20]. Our present data suggest that patients with gastrointestinal cancers have a higher than normal BMI regardless of age or tumor type. Forty percent of these patients have sarcopenia, which implies that preoperative physiotherapy is essential, along with nutritional therapy, in order to reduce the risk of adverse outcomes. Of note, physiotherapy can provide significant improvements within two weeks. Therefore, physiotherapy and nutritional intervention should be provided early (ideally at the time of diagnosis) in order to reduce the risk of surgical and other complications.

\section{Conflict of Interest}

The authors declare that they have no conflict of interest.

\section{References}

1. Vidal CA, Calleja FA, Villar TR, Urioste FA, Pintor de la MB, Hernández MA, Cano RI, Ballesteros P. Efficacy of enteral nutritional support after hospital discharge in major gastrointestinal surgery patients: a systematic review. Nutr Hosp 2017;34(3):719-26.
2. Mosquera C, Koutlas NJ, Edwards KC, Strickland A, Vohra NA, Zervos EE, Fitzgerald TL. Impact of malnutrition on gastrointestinal surgical patients. J Surg Res 2016;205(1):95-101.

3. Skeie E, Tangvik RJ, Nymo LS, Harthug S, Lassen K, Viste A. Weight loss and BMI criteria in GLIM's definition of malnutrition is associated with postoperative complications following abdominal resections - Results from a National Quality Registry. Clin Nutr 2019;39(5):1593-9.

4. Reber E, Gomes F, Vasiloglou MF, Schuetz P, Stanga Z. Nutritional risk screening and assessment. J Clin Med 2019;8(7):1065.

5. Lieffers JR, Bathe OF, Fassbender K, Winget M, Baracos VE. Sarcopenia is associated with postoperative infection and delayed recovery from colorectal cancer resection surgery. Br J Cancer 2012;107(6):931-6. 6. Prado CM, Baracos VE, McCargar LJ, Reiman T, Mourtzakis M, Tonkin K, Mackey JR, Koski S, Pituskin E, Sawyer MB. Sarcopenia as a determinant of chemotherapy toxicity and time to tumor progression in metastatic breast cancer patients receiving capecitabine treatment. Clin Cancer Res 2009;15(8):2920-6.

7. Han A, Bokshan SL, Marcaccio SE, DePasse JM, Daniels AH. Diagnostic criteria and clinical outcomes in sarcopenia research: a literature review. J Clin Med 2018;7(4):70.

8. Kontis V, Bennett JE, Mathers CD, Li G, Foreman K, Ezzati M. Future life expectancy in 35 industrialised countries: projections with a Bayesian model ensemble. Lancet 2017;389(10076):1323-35.

9. Nolen SC, Evans MA, Fischer A, Corrada MM, Kawas CH, Bota DA. Cancer-Incidence, prevalence and mortality in the oldest-old. A comprehensive review. Mech Ageing Dev. 2017;164:113-26.

10. Zhang R, Lu Y, Shi L, Zhang S, Chang F. Prevalence and patterns of multimorbidity among the elderly in China: a cross-sectional study using national survey data. BMJ Open. 2019;9:e024268.

11. Melis R, Marengoni A, Angleman S, Fratiglioni L. Incidence and predictors of multimorbidity in the elderly: a population-based longitudinal study. PLoS One 2014;9:e103120.

12. Venclauskas L, Maleckas A, Arcelus JI; ESA VTE Guidelines Task Force. European guidelines on perioperative venous thromboembolism prophylaxis: Surgery in the obese patient. Eur J Anaesthesiol 2018;35(2):147-53.

13. Cavagnari MAV, Silva TD, Pereira MAH, Sauer LJ, Shigueoka D, Saad SS, Barão K, Ribeiro CCD, Forones NM. Impact of genetic mutations and nutritional status on the survival of patients with colorectal cancer. BMC Cancer 2019;19(1):644.

14. Ogawa S, Yakabe M, Akishita M: Age-related sarcopenia and its pathophysiological bases. Inflamm Regen 2016;36:17-20.

15. Sanchis-Gomar F, Gómez-Cabrera MC, Viña J. The loss of muscle mass and sarcopenia: non hormonal intervention. Exp Gerontol 2011;46(12):967-9.

16. Chua MSH, Chan DKH. Increased morbidity and mortality of emergency laparotomy in elderly patients. World J Surg 2020;44(3):711-20. 17. Fearon KC, Ljungqvist O, Von Meyenfeldt M, Revhaug A, Dejong CH, Lassen K, Nygren J, Hausel J, Soop M, Andersen J, Kehlet H. Enhanced recovery after surgery: a consensus review of clinical care for patients undergoing colonic resection. Clin Nutr 2005;24(3):466-77.

18. Gustafsson UO, Scott MJ, Hubner M, Nygren J, Demartines N, Francis N, Rockall TA, Young-Fadok TM, Hill AG, Soop M, de Boer 
HD, Urman RD, Chang GJ, Fichera A, Kessler H, Grass F, Whang EE, Fawcett WJ, Carli F, Lobo DN, Rollins KE, Balfour A, Baldini G, Riedel B, Ljungqvist O. Guidelines for perioperative care in elective colorectal surgery: enhanced recovery after surgery (ERAS $®)$ society recommendations: 2018. World J Surg 2019;43:659-95.
19. Zhao B, Wu Lv, Lin J. Delaying adjuvant chemotherapy in advanced gastric cancer patients: risk factors and its impact on survival outcome. Curr Probl Cancer 2020:100577.

20. https://worldpopulationreview.com/countries/most-obese-countries/ 